EGU2020-22605

https://doi.org/10.5194/egusphere-egu2020-22605

EGU General Assembly 2020

(c) Author(s) 2021. This work is distributed under

the Creative Commons Attribution 4.0 License.

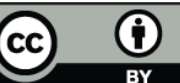

\title{
Multi-temporal geomorphological maps based on historical aerial images for the investigation of geomorphic changes in an Alpine catchment
}

Tobias Heckmann, Livia Piermattei, Jakob Rom, Moritz Altmann, Fabian Fleischer, Florian Haas, and Michael Becht

Physical Geography, University of Eichstätt-Ingolstadt, Eichstätt, 85072, Germany (tobias.heckmann@ku.de)

Since the end of the Little Ice Age, alpine geosystems have been subject to changes due to the effects of ongoing climate change, affecting e.g. the cryosphere, topography, surface materials and morphodynamics, landcover, landuse, and other anthropogenic factors. Our work forms part of the SEHAG project that investigates the sensitivity of alpine geosystems to climate change during that period.

In order to identify and assess such changes, we aim at generating multi-temporal geomorphological maps of three alpine catchments (Upper Kaunertal, Horlachtal, Austria; Val Martello, Italy). In contrast to "traditional" geomorphological maps, we do not use areal, linear and point symbols to represent landforms, their properties, and geomorphic processes. Our approach is entirely based on non-overlapping polygon features that represent a landform- and processcentered subdivision of the catchment. This enables the analysis of the resulting map in a GIS framework with respect to the type, size and other properties of landforms. Most importantly, it allows for the assessment of their spatial configuration (adjacency, topology) within the catchment in terms of toposequences and sediment cascades.

Mapping is based on photogrammetric products of aerial photos, that are orthophotos, digital elevation models (DEMs) and derivatives of the latter. Furthermore, DEMs can be used for the orientation of historical terrestrial photographs, making them an additional mapping basis through monoplotting. Depending on the availability of imagery (area-wide aerial images dating back to the mid of the $20^{\text {th }}$ century; local terrestrial photos starting from the second half of the $19^{\text {th }}$ century), an area-wide geomorphological map representing the present state of the system forms the basis of our investigations. Historical images are then used to "update" the map back into the past wherever differences to the temporally subsequent situation are conspicuous. This especially regards the massive decline of glaciers, but also the build-up and depletion of storage landforms, the development of lakes, and changes in the channel network.

At a later stage, the maps will be used for a network-based, multitemporal assessment of sediment connectivity. Nodes represent landforms contained in the geomorphological map(s), and all kinds of evidence (visible features indicating sediment transfer between adjacent landforms, 
measurements based on DEMs of difference, connectivity indices) will be used to establish edges that represent (potential) sediment transfer by geomorphic processes. As the configuration of system components and/or the activity of processes changes between maps of subsequent epochs, these changes will affect connectivity measures of the corresponding network model. 